borderline or low normal range, associated with significant learning disabilities. Language deficits are seen in all affected fragile $X$ males, even those with a normal IQ. Speech is described as jocular or staccato, in bursts which may include perseverations or repetition of words or phrases. Longitudinal IQ evaluations of fragile $X$ males have shown that younger boys score higher cognitively than adults. Heterozygous females may be completely unaffected by the syndrome or may have milder problems than those commoniy seen in the males. Approximately $30 \%$ of heterozygotes have cognitive deficits ranging from a borderline IQ to more significant retardation. Heterozygctes with normal IQ (approximately 70\%) have cognitive defects including a poor performance on Arithmetic, digit span and block design subtest scales on the WISC. Physical features in the mildly affected heterozygotes include prominent ears, double jointed thumbs, hyperextensible finger joints, and elongated face or prominent jaw in older females. Typical fragile $X$ facial features are reported in 55\% of retarded heterozygotes and in $14 \%$ of normal IQ heterozygotes. Enlargement of ovaries has been noted by ultrasound studies. (Hagerman R J and Sobesky W E. Psychopathology in fragile $X$ syndrome. Amer. J. Orthopsychiat. Jan 1989; 59:142-152).

COMMENT. This review article provides useful information about the clinical manifestations and psychopathology of heterozygous fragile $X$ females. Careful examination will often reveal subtle physical features associated with the fragile $X$ syndrome in females. Cognitive, social and emotional disorders are described. More detailed neuropsychological testing of heterozygotes has demonstrated learning disabilities in math, right left disorientation, constructional dyspraxia, and finger agnosia (Gerstmann's syndrome). (Grigsby $J$ et al. Neuropsychologia 1987; $25: 881)$.

\title{
MENTAL STATUS EXAMINATION
}

The child neurologists' approach to the mental status examination of children with learning problems was examined by questionnaires randomly submitted to 163 attendees at the 16th Annual Child Neurology Society Meeting in 1987 and the results are reported from the Division of Neurology, Department of Pediatrics, Newington Children's Hospital and Biostatistics Research Center, Farmington, Connecticut. The child neurologists were asked to score on a five point scale ( 0 =never, $5=$ always) the frequency with which they test for 30 mental status items when examining school ace children who present with learning problems. The 30 items were divided into six categories of mental status function in ascending order of complexity: 1) fundamental processes including level of responsiveness, attention and/or vigilance; 2) Language including handedness, spontaneous speech, comprehension, reading, writing, spelling; 3) Memory including orientation, immediate recal1, remote memory; 4) Constructional ability with reproduction drawings, drawings to command and block designs; 5) Higher cortical function for fund of information, proverb interpretation, similarities, calculations; 6) Related cortical function including ideomotor apraxia, ideational apraxia, right/left disorientation, finger agnosia, childhood Gerstmann, visual agnosia, and geographic orientation. The responders' frequency of testina in the six major categories of mental status function was independent of their age, sex, board certified/eligible status, type of practice and vears elapsed 
since completion of training. The results of the entire group and comparisons among demographic subgroups demonstrated a progressive decline in testing frequency with increasing complexity of mental status function. Higher and related cortical functions were tested significantly less often in children with learning problems than were the more elementary categories of mental status function. The diagnosis ascribed to a child with learning problems appeared to be based on findings other than those provided by the mental status examination. (Brunauell $\mathrm{P} J$ et al. Mental status examination of children with learning problems. Pediatric Neurclogy Jan-Feb 1989; $\underline{5}: 32-36$ ).

COMMENT. Pediatric neurologists are often consulted for the assessment of children with learning disabilities since many childhood learning disorders appear to have a primary neurologic basis. Sensory impairment, epilepsy, or progressive neurologic disease may require exclusion. The use of stimulant medication may need to be justified or its safety determined. The neurologist will use the all important history, the physical and neurological examination, an EEG and sometimes a neuro-imaging test. He will also rely on teacher evaluations and psychological testing by the school or privately. The results of this survey indicate that although the elementary aspects of mental status function (e.g. attention, vigilance, language) are almost always assessed in these children, higher and related cortical functions are relatively ignored or may not be practical in an office setting. However, it is relatively simple to test for Gerstmann syndrome and for defects in the fund of information and calculations. The Draw A Man test and parts of the Stanford-Binet may also be included in a routine pediatric neurology examination. Clinical-neuroanatomic correlations in LD children are not uncommon, particularly when the neurological exam is supplemented with the EEG, evoked potentials, and magnetic resonance imaging. In the future perhaps the mental status examination will play a larger role in the diagnosis of children with learning problems in the child neurologist's office setting.

BEHAVIORAL PROBLEMS IN TOURETTE SYNDROME

Behavioral and emotional difficulties in 78 males, 6-16 years of age, with Tourette syndrome were examined at the Departments of Neurology, Pediatrics, Psychiatry, and Education at Johns Hopkins University School of Medicine and School of Continuing Studies, Baltimore, Maryland. Symptoms most often identified ircluded obsessive compulsive behavior, aggressiveness, hyperactivity, immaturity, withdrawal and somatic complaints. Results were divided into two age groups, 6-11 years (21 patients) and 12-16 years (30 patients). Scores were abnormal in $24 \%$ of children and $43 \%$ of adolescents. In the younger age group, somatic complaints and obsessive compulsive scales were abnormal in $43 \%$, whereas in the older group more than $40 \%$ were described as being uncommunicative, obsessive compulsive, aggressive, hyperactive, immature and having hostile withdrawal. Delinquency, aggressiveness and hyperactive behavior were significantly increased in the older age group and abnormal behavioral profiles were more frequent in this age group. Tic severity was not a statistically significant predictor of behavioral disturbance, aithough a suggestive relationship between tic severity and behavioral disturbance was observed in the 12-16 year old group. Hyperactivity did not demonstrate an increased frequency of additional 